\title{
The frequency of nodular gastritis in adult patients and the relation of this type of gastritis with Helicobacter pylori and histopathologic findlings
}

\author{
Serkan Yalaki $\odot$ \\ Department of Gastroenterology, Mersin City Hospital, Mersin, Turkey
}

DOI: $10.18621 /$ eurj.420164

\begin{abstract}
Objectives: Endoscopic nodular gastritis is usually used to describe the miliary nodular appearance of the gastric mucosa during endoscopy. Recent studies have shown that nodular gastritis is closely related to Helicobacter pylori (H. pylori) infection and may cause stomach cancer, especially in young women. We aimed to determine the frequency of nodüler gastritis in this study, other lesions seen during endoscopy, $H$. pylori frequency and histopathological findings.

Methods: Adult patients who underwent endoscopy between March 2015 and April 2017 were identified. Medical records of patients; demographic characteristics, endoscopic features and pathologic were investigated retrospectively. Patients with nodular gastritis were compared with age and gender matched control group.

Results: Of the 1877 patients evaluated, 39 patients with endoscopic nodular gastritis and 72 as control group were enrolled. The prevalence of $H$. pylori infection was significantly higher in patients with endoscopic nodular gastritis than in the control group $(74.35 \%$ versus $63.88, p<0.0001)$. The most common concurrent endoscopic findings were erosions (25.64\%). Histopathologically, the prevalence of atrophic gastritis and intestinal metaplasia in the patients with endoscopic nodular gastritis was also higher than in the control group $(p<0.05)$. Conclusions: Nodular gastritis is often caused by chronic H. pylori infection. It is observed more frequently in women and children. Most patients with $H$. pylori infection have no specific symptom or complication, but some patients may develop premalign conditions such as active gastritis, atrophic gastritis and intestinal metaplasia. For this reason, H. pylori eradication in patients with nodular gastritis may reduce the development of peptic ulcer and possibly gastric malignancy.
\end{abstract}

Keywords: Helicobacter pylori, nodular gastritis, atrophic gastritis, metaplasia

Received: May 1, 2018; Accepted: April 30, 2019; Published Online: June 30, 2019

$H$ elicobacter pylori (H. pylori) is a gram-negative bacteria which has the ability to be colonized in and to infect the stomach. After feco-oral transmission, the bacteria pierces the mucous membrane of the stomach and settles on the luminal surface of the stomach, then causes an intense inflammatory response.
H. pylori infection is strongly associated with the risk of stomach cancer. Stomach cancer rates vary between countries. These differences can be explained by the variability in the $H$. pylori genotypes and their variability in the expression of the cagA and vacA genes (virulence genes associated with the develop-

Address for correspondence: Serkan Yalaki, MD., Mersin City Hospital, Department Gastroenterology, Mersin Entegre Sağlık Kampüsü, Korukent Mah., 96015 Sok., 33240 Toroslar, Mersin, Turkey 
ment and progression of gastric atrophy). It is known that CagA-positive H. pylori infection is responsible for various gastric diseases such as chronic gastritis, gastroduodenal ulcers, mucosa associated lymphoid tissue lymphoma, immunological thrombocytopenia and stomach cancer [1]. It is known that there are precursor lesions as superficial gastritis-atrophic gastritis-intestinal metaplasia-gastric displasia before stomach cancer occurs [2].

Endoscopic nodular gastritis is usually used to describe the miliary nodular appearance (similar to chicken skin) of the gastric mucosa during endoscopy. There is no consensus about the precise endoscopic definition of nodular gastritis and whether it can be classified as an acute or chronic lesion. Nodular gastritis is a well-known, common form of $H$. pylori infection in children. It characterized by the pathologically distinct lymphoid follicles in the stomach antrum and the infiltration of mononuclear cells. Macroscopic nodularity is thought to be a reflection of the presence of these lymphoid follicles [3-4]. Recent studies have shown that nodular gastritis is closely associated with $H$. pylori infection and may cause stomach cancer, especially in young women [5].

In this study, it was aimed to determine the frequency of nodular gastritis and the relationship of this gastritis with $H$. pylori among adult patients who were evaluated endoscopically in our clinic; and at the same time, it is aimed to reveal the demographic data and associated histopathological findings of patients with nodular gastritis.

\section{METHODS}

A total of 1877 adult patients underwent endoscopy between March 2015 and April 2017 were identified. The medical records were retrospectively reviewed regarding the demographic characteristics, clinical features, endoscopic features and pathologic features of the patients. Thirty-nine patients with nodular gastritis were included in the study. Endoscopic nodular gastritis was defined as a miliary nodular appearance in the antrum and/or corpus of the gastric mucosa on the endoscopy. The control group consisted of 72 randomly selected patients whose biopsies were taken and had an endoscopic appearance of 3 normal. All endoscopic procedures were performed by a specialist gastroenterologist with a high resolution white light source endoscopy instrument (Olympus). Two biopsies from the antrum and two biopsies from the corpus were taken from all patients in the control group with endoscopic nodular gastritis. Biopsy specimens were fixed in $10 \%$ formalin and transferred to the laboratory under appropriate conditions. Giemsa, and hematoxylin and eosin staining were performed to detect $H$. pylori histologically.

\section{Statistical Analysis}

Comparisons between the two groups were analyzed using chi-square test for categorical variables and t-test for continuous variables. Two-way $\mathrm{p}<0.05$ values were considered statistically significant. Statistical analyzes were performed with SPSS 15.0. The proportions of pathological lesions were adjusted according to gender and age, and analyzed with logistic regression.

\section{RESULTS}

The mean age of the patients with endoscopic nodular gastritis and control group was $47.19 \pm 15.32$ years and $46.72 \pm 14.26$ years, respectively. Patient ages ranged from 17 to 91 years. In the study group $14(35.89 \%)$ males and $25(64.10 \%)$ females were detected.

In adults who underwent endoscopy, the incidence of nodular gastritis was $1.97 \%$ (39/1877). Histological H. pylori infection was detected in $74.35 \%$ of patients with endoscopic nodular gastritis, whereas this rate was $63.88 \%$ in the control group. The prevalence of H. pylori infection was significantly higher in patients with endoscopic nodular gastritis than in the control

Table 1. Endoscopic findings accompanying gastric nodules.

\begin{tabular}{lcc}
\hline Endoscopic findings & $\mathbf{n}$ & $\mathbf{\%}$ \\
\hline Erosion & 10 & 25.64 \\
Bulbit & 9 & 23.07 \\
Duodenal ulcer & 4 & 10.25 \\
Gastric ulcer & 1 & 2.56 \\
Gastric polyp & 1 & 2.56 \\
\hline
\end{tabular}


Table 2. Histopathological findings

\begin{tabular}{lcc}
\hline & $\begin{array}{c}\text { Study group } \\
\mathbf{n = 3 9}\end{array}$ & $\begin{array}{c}\text { Control group } \\
\mathbf{n}=\mathbf{7 2}\end{array}$ \\
\hline Atrophic gastritis & $2(5.12 \%))$ & $2(2.77 \%)$ \\
Intestinal metaplasia & $3(7.69 \%)$ & $2(2.77 \%)$ \\
Dysplasia & - & - \\
Lymphoid follicle & $12(30.76 \%)$ & $11(15.27 \%)$ \\
\hline
\end{tabular}

group $(p<0.0001)$.

Regarding the endoscopic findings in 39 patients with nodular gastritis, noduls were found in 27 $(69.23 \%)$ patients in the antrum and in $12(30.76 \%)$ patients in the other regions in addition to antrum. Duodenal ulcer was found in $4(10.25 \%)$ patients, gastric ulcer in $1(2.56 \%)$ patient and erosive gastritis in $10(25.64 \%)$ patients. In $9(23.07 \%)$ of the patients bulbitis besides gastritis was detected. One $(2.56 \%)$ patient had gastric polyps. There was no appearance suggesting atrophy, metaplasia or stomach cancer (Table 1).

In the histopathological examination, the rate of atrophic gastritis in endoscopic nodular gastritis patients and control group were 5.12\% (2/39) and $2.77 \%(2 / 72)$, respectively. Intestinal metaplasia was detected in $7.69 \%$ (3/39) of patients with endoscopic nodular gastritis, but only $2.77 \%$ of the control group had intestinal metaplasia findings. These findings were statistically significant $(p<0.05)$. Lymphoid follicle formation was higher in patients with nodular gastritis $(30.76 \%)$ than in the control group $(15.27 \%)(p<$ 0.05) (Table 2). Displasia was not found histopathologically in neither the study group nor the control group.

\section{DISCUSSION}

While the prevalence of nodular gastritis in this study was $1.97 \%$, Chen et al. [6] reported a rate of 2.9\%; Miyamoto et al. [7] 0.19\%; Önal İK et al. [8], 1.86\%; Maghidman et al. [9] 7.2\%. These differences in proportions may be due to sample selection. Symptomatic patients were taken in our study; studies reporting a lower prevalence rate also included symptomatic and asymptomatic individuals during endoscopy. Other reasons for variability in prevalence may be related to study design, host, bacterial or environmental variables. On the other hand, there is no common definition for the endoscopical appearance of nodules and the term "nodular gastritis" needs to be clarified further. The great difference in nodular gastritis prevalence in various studies may be mainly due to this subjective definition of endoscopists instead of different $H$. pylori prevalence among study groups.

As in previous studies [6-10], we have seen that female patients are affected more than men. The incidence of $H$. pylori infection does not differ according to sex, but the high proportion of women corresponds to this idea. However, it supports the hypothesis that the result of $H$. pylori infection may be related to a sex-specific host immune factor [11].

Previous studies have reported H. pylori positivity in $67-98.5 \%$ of patients with nodular gastritis [6-10].In our study, the prevalence of $H$. pylori in patients with nodular gastritis was $74.35 \%$ which is higher than the control group (63.88\%). Several studies suggest that the presence of antral nodularity is highly indicative of $H$. pylori infection. Similarly, it has been suggested that the specificity and the positive predictive value of nodular gastritis for $H$. pylori infection are high $[12,13]$. For this reason, endoscopically detected nodular gastritis may be indicative of the possibility of $H$. pylori infection.

In this study, atrophic gastritis and intestinal metaplasia were more frequent in patients with endoscopic nodular gastritis. Dysplasia is not detected in neither of the groups. These results were consistent with the literature [8-10, 14-16].

Our study revealed that the formation of lymphoid follicle and/or aggregate was more frequent in patients with $H$. pylori positive nodular gastritis. In a series of 261 patients, Maghidman et al. [9] found that nodular gastritis was not associated with the presence and 
number of lymphoid follicles. In contrast, Sokmensuer et al. [14] have shown that intraepithelial lymphocytosis is more prominent in nodular gastritis patients and may contribute to nodule formation. Rafeey et al. [15] have shown that nodular gastritis frequency is associated with the presence, density and histological grade of gastritis of $H$. pylori infection. Nodularity is probably associated with the intensity of $H$. pylori at the onset of infection, so large inoculations trigger an exaggerated immune response [16]. $H$. pylori is predominantly acquired in childhood and nodular gastritis is often found in children who undergo endoscopy [12, 15]. However, nodular gastritis is present in the minority of adult patients with $H$. pylori infection. It is not clear how and why this particular model develops in only a small part of adult patients. Variations in bacterial strains, host factors, or complex interactions between host and bacterial factors have all been considered as explanations [17].

In this study, none of the patients had stomach cancer. Recent studies have shown that nodular gastritis is closely associated with $H$. pylori infection and may cause gastric cancer in young women in particular [5]. The prevalence of premalign lesions such as atrophic gastritis and metaplasia was higher than that of non-nodular gastritis group, although dysplasia was not detected in this study. These results were consistent with other studies in the literature [5, $8-10,16,17]$. On the other hand, the high prevalence of $H$. pylori infection in histologic premalign lesions and in cancer patients has been described $[17,18]$. For this reason, $H$. pylori infection may be one of the possible causes of histologic premalign lesions in endoscopic nodular gastritis patients.

\section{CONCLUSION}

Nodular gastritis is caused by chronic H. pylori infection. They are more common in women and children. Patients infected with $H$. pylori at an early age do not have a specific symptom or complication in the majority, but some patients may develop premalign conditions such as active gastritis, atrophic gastritis and intestinal metaplasia. For this reason, $H$. pylori eradication in patients with nodular gastritis possibly reduces the risk of peptic ulcer and gastric malignancy. The definition and clinical significance of nodular gastritis and associated histopathology will become clearer with prospective long-term follow-up studies, including a large number of patients.

\section{Conflict of interest}

The author disclosed no conflict of interest during the preparation or publication of this manuscript.

\section{Financing}

The author disclosed that they did not receive any grant during conduction or writing of this study.

\section{REFERENCES}

[1] Graham DY. Helicobacter pylori update: gastric cancer, reliable therapy, and possible benefits. Gastroenterology 2015;148:719-31.e3.

[2] Correa P, Piazuelo MB. The gastric precancerous cascade. J Dig Dis 2012;13:2-9.

[3] Hassall E, Dimmick JE. Unique features of Helicobacter pylori disease in children. Dig Dis Sci 1991;36:417-23.

[4] De Giacomo C, Fiocca R, Villani, Listo L, Licardi G, Diegoli N. Helicobacter pylori infection and chronic gastritis: clinical, serological, and histologic correlations in children treated with amoxicillin and colloidal bismuth subcitrate. J Pediatr Gastroenterol Nutr 1990;11:310-6.

[5] Kamada T, Tanaka A, Yamanaka Y, Manabe N, Kusunoki H, Miyamoto M, et al. Nodular gastritis with Helicobacter pylori infection is strongly associated with diffuse-type gastric cancer in young patients. Dig Endosc 2007;19:180-4.

[6] Chen MJ, Wang TE, Chang WH, Liao TC, Lin CC, Shih SC. Nodular gastritis: an endoscopic indicator of Helicobacter pylori infection. Dig Dis Sci 2007;52:2662-6.

[7] Miyamoto M, Haruma K, Yoshihara M, Hiyama T, Sumioka M, Nishisaka T, et al. Nodular gastritis in adults is caused by Helicobacter pylori infection. Dig Dis Sci 2003;48:968-75.

[8] Önal İK, Sökmensüer C, Demir Önal E, Ersoy O, Yeniova Ö, Aydınlı M, et al. Clinical and pathological features of nodular gastritis in adults. Turk J Med Sci 2009;39:719-23.

[9] Maghidman S, Cok J, Bussalleu A. Histopathological findings in nodular gastritis. Experience at the Cayetano Heredia National Hospital. Rev Gastroenterol Peru 2001;21:261-70.

[10] Nakashima R, Nagata N, Watanabe K, Kobayakawa M, Sakurai T, Akiyama J. Histological features of nodular gastritis and its endoscopic classification. J Dig Dis 2011;12:436-42.

[11] Kusters JG, van Villet AH, Kuipers EJ: Pathogenesis of Helicobacter pylori infection. Clin Microbiol Rev 2006;19:44990.

[12] Kato S, Yoshikazu N, Kyoko O, Konno M, Shun-ichi M, Toyoda S, et al. The prevalence of Helicobacter pylori in Japanese children with gastritis or peptic ulcer disease. J Gastroenterol 2004;39:734-8. 
[13] Bahu Mda G, da Silveira TR, Maguilnick I, UlbrichKulczynski J. Endoscopic nodular gastritis: an endoscopic indicator of high-grade bacterial colonization and severe gastritis in children with Helicobacter pylori. J Pediatr Gastroenterol Nutr 2003;36: 217-22.

[14] Sokmensuer C, Onal IK, Yeniova O, Ersoy O, Aydinli M, Yonem $\mathrm{O}$, et al. What are the clinical implications of nodular gastritis? Clues from histopathology. Dig Dis Sci 2009;54:21504.

[15] Rafeey M, Jafari Rouhi AH, Gassemi BA, Rouhi AJ. Relationship between endoscopic nodular gastritis and Helicobacter pylori infection in children. Indian J Gastroenterol 2004;23:138-9.
[16] Niknam R, Manafi A, Maghbool M, Kouhpayeh A, Mahmoudi L. Is endoscopic nodular gastritis associated with premalignant lesions? Neth J Med 2015;73:236-41.

[17] Chen MJ, Shih SC, Wang TE, Chan YJ, Chen CJ, Chang WH. Endoscopic patterns and histopathological features after eradication therapy in Helicobacter pylori-associated nodular gastritis. Dig Dis Sci 2008;53:1893-7.

[18] Konturek PC, Konturek SJ, Brzozowski T. Helicobacter pylori infection in gastric cancerogenesis. J Physiol Pharmacol 2009;60:3-21.

[19] Nardone G, Rocco A, Malfertheiner P. Review article: Helicobacter pylori and molecular events in precancerous gastric lesions. Aliment Pharmacol Ther 2004;20:261-70. 